\title{
Achados de formas jovens e adultas de Fasciola hepatica (Linnaeus, 1758) em bovinos durante inspeção post-mortem
}

\author{
The finding of young and adult forms of Fasciola hepatica \\ (Linnaeus, 1758) in cattle during post-mortem inspection
}

Veridiana Pierosan da Silva Ribeiro ${ }^{[a]}$, Selene Cirio Leite ${ }^{[b]}$, Wanderley Francisco Lehmkuhl[c], Ana Carolina Bazo Zadorosnei ${ }^{[a]}$, Sergio Silva Borges ${ }^{[d]}$, Marcelle Cirio Leite ${ }^{[e]}$, Matheus Folgearini Silveira[f], Luiz Carlos Leite ${ }^{[9]}$

[a] Médicas veterinárias autônomas, Curitiba, PR - Brasil, e-mails: veryou38@yahoo.com.br; anacarolinavet@bol.com.br

[b] Médica veterinária, mestranda do curso de Ciências Biológicas, Universidade Federal do Paraná (UFPR), Curitiba, PR Brasil, e-mail: seleneleite@gmail.com

[c] Médico veterinário, fiscal federal agropecuário, Ministério da Agricultura, Pecuária e Abastecimento (MAPA), Colorado, PR - Brasil, e-mail: wflehmkuhl@uol.com.br

[d] Médico veterinário, gerente de inspeção de produtos de origem animal, Companhia Integrada de Desenvolvimento Agrícola de Santa Catarina (CIDASC), Florianópolis, SC - Brasil, e-mail: geinp@cidasc.sc.gov.br

[e] Acadêmica do curso de bacharelado em Ciências Biológicas, Pontifícia Universidade Católica do Paraná (PUCPR), Curitiba, PR - Brasil, e-mail: mar_leite92@hotmail.com

[f] Médico veterinário, mestre em Sanidade Animal, professor do Instituto Federal Catarinense (IFC), Araquari, SC - Brasil, e-mail: matheus.silveira@ifc-araquari.edu.br

[g] Médico veterinário, doutor em Ciências Biológicas, professor do Instituto Federal Catarinense (IFC), Araquari, SC - Brasil, e-mail: lcmouraleite@gmail.com; luiz.leite@ifc-araquari.edu.br

\section{Resumo}

A fasciolose hepática desencadeia processo inflamatório crônico no fígado e órgãos anexos de animais domésticos e silvestres, levando, em alguns casos, à calcificação e obstrução de ductos biliares. A afecção é causada por Fasciola hepatica (Platyhelminthes: Trematoda: Digenea), um helminto responsável por consideráveis perdas econômicas em animais de produção. Os sinais variam de acordo com a fase, localização, duração da infecção e número de exemplares adultos presentes nos órgãos afetados. Na fase aguda da doença a migração larval no organismo do hospedeiro provoca diarreia, má digestão e absorção, icterícia, hepatomegalia, leucocitose e eosinofilia. Na fase crônica, os parasitos adultos presentes no interior de canais e ductos biliares induzem inflamação e obstrução. Hospedeiros portadores da doença crônica apresentam cirrose hepática, perda de peso e baixa resistência, ocasionalmente resultando em morte do paciente. Os seres humanos são considerados hospedeiros acidentais. 0 presente relato descreve três achados de formas adultas 
de F. hepatica em fígados e um caso de migração errática de parasitos jovens, reportados durante trabalhos de inspeção post-mortem de bovinos em frigorífico sob inspeção federal (SIF) no estado do Paraná.

Palavras-chave: Fasciolose. Parasito. Trematoda. Zoonose.

\section{Abstract}

Hepatic fascioliosis unleashes a chronic inflammatory process in the liver and connected organs of domestic and wild animals, leading, in some cases, to calcification and obstruction of bile ducts. This condition is caused by Fasciola hepatica (Platyhelminthes: Trematoda: Digenea), a helminth responsible for considerable economic losses in livestock production. Symptoms vary according to the stage, location, duration of infection and number of adult specimens present in the affected organs. In the acute stage of the disease, larval migration in the host organism causes hepatomegaly, anemia, fever, subcutaneous edema, leukocytosis, eosinophilia, hypoproteinemia, diarrhea, indigestion and jaundice. During the chronic stage, the adult parasites induce inflammation and obstruction of bile canals and ducts. In addition, animals at the chronic stage present cirrhosis, weight loss and low resistance, occasionally leading to death. Humans are considered accidental hosts. This study describes the presence of adult forms of F. hepatica in 3 livers and one case of erratic migration of young parasites in cattle, reported during post-mortem inspections at a slaughterhouse under the federal inspection service (SIF) in the State of Parana.

Keywords: Fascioliosis. Parasite. Diseases. Trematoda. Zoonosis.

\section{Introdução}

Considerada uma importante zoonose (KAPLAM, 2001; OROPEZA et al., 2003; YASGAN et al., 2006; OLIVEIRA et al., 2007; ALIZADEH et al., 2011), a fasciolose hepática desenvolve processo inflamatório crônico no fígado e vesícula biliar. A doença é causada por Fasciola hepati$c a$, parasito de grandes e pequenos ruminantes e várias espécies de animais silvestres e domésticos (SILVA SANTOS; SCAINI; RODRIGUES, 1992; MARQUES; SCROFERNEKER, 2003; ARAÚJO et al., 2007; AMOR et al., 2011). A ação do helminto causa prejuízo econômico à pecuária mundial devido à condenação de fígados dos animais afetados (BOSTELMANN et al., 2000; MWABONIMANA et al., 2009; BALA; GARBA; YAZAH, et al., 2011; BERNARDO et al., 2011; OZUNG; OWAI; ONI, 2011). Paralelamente é registrada queda na produção, atraso no crescimento e mortalidade. De distribuição mundial, a enfermidade ocorre principalmente em regiões de condições climáticas e ambientais adequadas ao desenvolvimento do parasito como umidade do solo, precipitações pluviométricas e temperatura entre 10 e $25^{\circ} \mathrm{C}$, que igualmente interferem de maneira favorável no desenvolvimento dos hospedeiros intermediários de $F$. hepatica. Os estados de Goiás, Rio Grande do Sul, Espírito Santo, Pará, Paraná, Santa Catarina, São Paulo, Minas Gerais e Rio de Janeiro apresentam consideráveis índices de fasciolose (BOSTELMANN et al., 2000; QUEIROZ et al., 2002; MARQUES; SCROFERNEKER, 2003; ARAÚJO et al., 2007; MENDES; PILATI, 2007; DUTRA et al., 2010; OLIVEIRA; SPÓSITO FILHA, 2009; BERNARDO et al., 2011). 0 ciclo biológico envolve a eliminação dos ovos da $F$. hepatica com as fezes do hospedeiro definitivo para o meio externo. Em contato com a água os ovos embrionam e dão origem aos miracídios, formas infectantes, que após a eclosão procuram os hospedeiros intermediários, caramujos do gênero Lymnaea (OLIVEIRA; SPÓSITO FILHA, 2009). Após a penetração no molusco, o miracídio evolui para esporocisto, rédia e cercária entre seis e sete semanas. As cercárias abandonam o hospedeiro intermediário, movem-se através da água e se aderem a plantas aquáticas. Ali evoluem para a forma de metacercárias, sendo ingeridas por animais que utilizam estes locais 
como bebedouros e as plantas como alimentação. De acordo com Kaplan (2001), a principal forma de transmissão da doença em animais e seres humanos é através da ingestão de água ou plantas contaminadas com metacercárias, ocorrendo variação nos sinais e sintomas desencadeados pela fase, duração do processo infeccioso e quantidade de formas parasitárias.

Conforme Bostelmann et al. (2000), o parasito necessita de quatro a cinco meses para completar seu ciclo nos hospedeiros intermediário e definitivo. Na fase aguda, a súbita invasão do fígado por um grande número de trematodas imaturos ocasiona destruição do parênquima pela migração, insuficiência hepática e hemorragia na cavidade peritoneal, levando à hepatite aguda hemorrágica. A migração larval provoca dor abdominal, fraqueza progressiva, hepatomegalia, anemia, diarreia, febre, edema subcutâneo e leucocitose. Entre um e três meses após a ingestão das metacercárias pelo hospedeiro definitivo, o parasito atinge a forma adulta no interior dos ductos e canais biliares (OLIVEIRA; SPÓSITO FILHA, 2009; OZUNG; OWAI; ONI, 2011). Um helminto adulto pode sobreviver até 11 anos alojado no interior do parênquima hepático do hospedeiro. As manifestações clínicas da doença observadas em infecções crônicas frequentemente são caracterizadas por diminuição no peso, hipoproteinemia, eosinofilia, depressão, inflamação, anemia, necrose de coagulação, fibrose difusa do parênquima hepático, dilatação, cirrose (FROMSA; MEHARENET; MEKIKIB, 2011), estenose, obstrução e calcificação dos canais biliares. Estas lesões podem predispor os animais acometidos a infecções bacterianas secundárias provocadas por Clostridium novyi e Clostridium haemoliticum, resultando na morte do indivíduo (LOBATO et al., 2007).

O homem, considerado hospedeiro acidental de $F$. hepatica, normalmente apresenta manifestações de natureza grave, como dor abdominal, hepatomegalia, inflamação e cirrose. Cinquenta e sete casos de fasciolose humana foram descritos no Brasil nos estados do Paraná, Santa Catarina, Minas Gerais, Bahia, Rio de Janeiro, Mato Grosso do Sul, Rio Grande do Sul e Amazonas nos últimos dez anos (CALRETAS et al., 2003; CORAL; MASTALIR; MASTALIR, 2007; ARAÚJO et al., 2007; OLIVEIRA et al., 2007). Também foram registrados casos de parasitismo humano na Inglaterra, Chile, Porto Rico,
Argentina, São Domingos, Cuba, México, França, Venezuela, Portugal, Iran e Peru (OROPEZA et al., 2003; YASGAN et al., 2006; ARAÚJO et al., 2007; FREITES et al., 2009; IBIRONKE; FASINA, 2010; ALIZADEH et al., 2011).

O objetivo do presente trabalho foi relatar a ocorrência de fasciolose hepática no estado do Paraná e sua importância em saúde pública e saúde animal.

\section{Material e métodos}

No período entre 12 de julho e 25 de outubro de 2010, 29.054 bovinos mestiços zebu devidamente identificados, procedentes de 114 municípios do estado do Paraná, foram abatidos e inspecionados em frigorífico sob supervisão do Serviço de Inspeção Federal (SIF), no município de Colorado (PR), conforme tecnologia padrão empregada para bovinos. Os trabalhos de inspeção nas linhas foram realizados por uma equipe de agentes devidamente treinados para realizar a inspeção post-mortem sob supervisão e responsabilidade do médico veterinário do SIF. Os exames de rotina desenvolvidos na pesquisa da fasciolose bovina e adotados nas linhas de inspeção foram baseados nas normas de padronização do SIF do Ministério da Agricultura, Pecuária e Abastecimento (MAPA), sendo condenados os fígados portadores de formas jovens e adultas de Fasciola hepatica.

\section{Resultados e discussão}

Durante as inspeções post-mortem de rotina envolvendo 29.054 bovinos, foram encontrados três exemplares adultos de Fasciola hepatica $(0,01 \%)$ no interior dos ductos biliares do fígado de três animais provenientes do município de Loanda (PR). Foram detectadas formas jovens do parasito inseridas na vesícula biliar de um bovino abatido, mas neste caso não foi possível precisar qual o local de origem do animal afetado. Os fígados infectados foram classificados como impróprios para o consumo. As respectivas carcaças não apresentaram alterações de quaisquer outras ordens, sendo posteriormente liberadas para comercialização. Queiroz et al. (2002) e Dutra et al. (2010) igualmente registraram casos positivos de F. hepatica bovina nos 
municípios paranaenses de Bocaiúva do Sul, Cerro Azul, Japira, Lapa e Palmital, comprovando a ocorrência da enfermidade no estado do Paraná.

Mesmo com suas limitações, a inspeção é utilizada na rotina, servindo como indicativo do grau de infecção em uma determinada propriedade ou mesmo na comunidade. Um grande obstáculo encontrado na correta identificação da doença em bovinos é a realização do abate clandestino de muitos animais em propriedades rurais, sem práticas de higiene e fiscalização e sem os devidos exames exigidos pelo serviço de inspeção (BOSTELMANN et al., 2000). A fiscalização é dificultada pela própria legislação vigente que autoriza a ação de fiscais apenas munidos de ordem judicial. A adoção de abates comunitários eliminará o problema sanitário, uma vez que o trabalho será feito em estabelecimento legalizado e sob fiscalização oficial. É de grande importância a conscientização dos proprietários para o perigo que representam os abates clandestinos. Conforme dados fornecidos pelo Serviço de Inspeção Federal do Ministério da Agricultura, Pecuária e Abastecimento (SIF/ MAPA), entre 2003 e 2008 no estado do Paraná foram abatidos 6.727 .459 bovinos, e 48.235 (0,71\%) fígados que albergavam exemplares de $F$. hepatica foram condenados nas linhas de inspeção (DUTRA et al., 2010). Este resultado é significativamente superior ao encontrado na presente pesquisa.

Os resultados encontrados no presente trabalho também foram menores em comparação aos registrados por Ozung, Owai e Oni (2011) na Nigéria, que comprovaram parasitismo por $F$. hepatica em 75 fígados $(7,35 \%)$ de 1020 bovinos abatidos entre janeiro de 1995 e dezembro de 1999 e por Ibironke e Fasina (2010), neste mesmo país, os quais diagnosticaram a presença de $F$. hepatica em $8.428(0,72 \%)$ fígados em 1.170 .492 bovinos abatidos em Lagos, Nigéria. 0 índice também foi inferior ao reportado no estado do Espírito Santo por Bernardo et al. (2011) que apontou 27.625 fígados $(24,89 \%)$ parasitados por $F$. hepatica provenientes de 110.956 bovinos abatidos entre 2006 e 2009 . Sousa et al. (2011) não detectaram ocorrência deste parasito em $1.206(5,8 \%)$ fígados provenientes de 20.760 animais abatidos entre março de 2010 e fevereiro de 2011, em frigorifico sob inspeção federal do MAPA em Santarém (PA), descartados por albergarem outras formas de lesões hepáticas.

\section{Conclusões}

Apesar do baixo número de casos positivos diagnosticados no presente trabalho, o Paraná é um dos estados brasileiros que apresenta ocorrência de $F$. hepatica no rebanho bovino. 0 controle eficiente desta parasitose envolve a utilização de substâncias de comprovada eficácia no combate às suas fases larval e adulta, associada à redução dos hospedeiros intermediários, empregando-se de maneira correta e eficaz os controles químico, físico e biológico.

\section{Agradecimentos}

Agradecemos à Médica Veterinária Dra. Anelise Maria Bosco pelo material gentilmente cedido. Os autores dedicam este trabalho à memória do Prof. Ennio Luz.

\section{Referências}

ALIZADEH, A. H. M. et al. Cholangiocarcinoma in magnetic resonance cholangiopancreatography and fascioliasis in endoscopic ultrasonography. Case Reports in Gastroenterology, v. 5, n. 3, p. 569-577, 2011. doi:10.1159/000333229.

AMOR, N. et al. First report of Fasciola hepatica in Equus caballus host species from Tunisia based on the ribosomal internal transcribed spacer regions. Turkish Journal of Veterinary and Animal Sciences, v. 35, n. 5, p. 319, 2011.

ARAÚJO, J. L. B. et al. Infecções autóctones de bovinos por Fasciola hepatica Linnaeus, 1758 (Trematoda, Fasciolidae) no Estado de Goiás, Brasil. Revista de Patologia Tropical, v. 36, n. 1, p. 96-100, 2007.

BALA, A. N.; GARBA, A. E.; YAZAH, A. J. Bacterial and parasitic zoonoses encountered at slaughter in Maiduguri abattoir, north-eastern Nigeria. Veterinary World, v. 4, n. 10, p. 437-443, 2011. doi:10.5455/vetworld.2011.437-443

BERNARDO, C. C. et al. Prevalence of liver condemnation due to bovine fasciolosis in southern Espírito Santo: temporal distribution and economic losses. Revista Brasileira de Parasitologia Veterinária, v. 20, n.1, p. 49-53, 2011. doi:10.1590/S1984-29612011000100010. 
BOSTELMANN, S. C. W. et al. Histopatologia comparativa em fígados de bovinos, bubalinos e ovinos infectados por Fasciola hepatica. Archives of Veterinary Science, v. 5, n. 1, p. 95-100, 2000.

CALRETAS, S. et al. Seis casos de fasciolíase hepática. Medicina Interna, v. 10, n. 4, p. 185-192, 2003.

CORAL, R. P.; MASTALIR, E. T.; MASTALIR, F. P. Retirada de Fasciola hepatica da via biliar principal por coled ocoscopia. Revista do Colégio Brasileiro de Cirurgiões, v. 34, n. 1, p. 69-71, 2007. doi:10.1590/S0100-69912007000100016.

DUTRA, L. H. et al. Mapping risk of bovine fasciolosis in the south of Brazil using Geographic Information Systems. Veterinary Parasitology, v. 169, n. 1-2, p. 7681, 2010. doi:10.1016/j.vetpar.2009.12.015.

FREITES, A. et al. Fasciolosis humana en el municipio Mara, estado Zulia, Venezuela: prevalencia y factores asociados. Investigación Clínica, v. 50, n. 4, p. 497-506, 2009.

FROMSA, A.; MEHARENET, B.; MEKIKIB, B. Major trematode infections of cattle slaughtered at Jimma Municipality Abbatoir and the ocurrence of the intermediate hosts in selected water bodies of the zone. Journal of Animal and Veterinary Advances, v. 10, n. 12, p. 1592-1597, 2011. doi:10.3923/javaa.2011.1592.1597.

IBIRONKE, A. A.; FASINA, F. O. Socio-economic implications of bovine liver rejection in a major abattoir in southwestern Nigeria. Revista de Ciências Agrárias, v. 33, n. 2, p. 211-216, 2010.

KAPLAN, R. M. Fasciola hepatica: a review of the economic impact in cattle and considerations for control. Veterinary Therapeutics, v. 2, n. 1, p. 40-50, 2001. PMid:19753697.

LOBATO, F. C. F.; SALVARANI, F. M.; ASSIS, R. A. Clostridioses dos pequenos ruminantes. Revista Portuguesa de Ciências Veterinárias, v. 102, n. 561-562, p. 23-34, 2007.

MARQUES, S. M. T.; SCROFERNEKER, M. L. Fasciola hepatica infection in cattle and buffaloes in the State of Rio Grande do Sul, Brazil. Parasitologia Latinoamericana, v. 58, n. 3-4, p. 169-172. 2003. doi:10.4067/ S0717-77122003000300015.

MENDES, R. E.; PILATI, C. Estudo morfológico de fígado de bovinos abatidos em frigoríficos industriais sob inspeção estadual no Oeste e no Planalto de Santa Catarina, Brasil. Ciência Rural, v. 37, n. 6, p. 1728-1734, 2007. doi:10.1590/S0103-84782007000600035.
MWABONIMANA, M. F. et al. Prevalence and economic significance of bovine fasciolosis in slaughtered cattle at Arusha abattoir, Tanzania. Tanzania Veterinary Journal, v. 26, n. 2, p. 68-74, 2009. doi:10.4314/tvj.v26i2.53804.

OLIVEIRA, A. A. et al. Estudo da prevalência e fatores associados à fasciolose no município de Canutama, Estado do Amazonas, Brasil. Epidemiologia e Serviços de Saúde, v. 16, n. 4, p. 251-259, 2007.

OLIVEIRA, S. M.; SPÓSITO FILHA, E. Fasciolose hepática. Biológico, v. 71, n. 1, p. 5-7, 2009.

OROPEZA, D. L. et al. Hematoma hepático subcapsular por fasciola. Revista de Gastroenterología del Perú, v. 23, n. 2, p. $142-148,2003$

OZUNG, P. O.; OWAI, P. U.; ONI, K. O. An assessment of the prevalence of fascioliasis of ruminants in Ikom Abattoir of Cross River State, Nigeria. Continental Journal of Veterinary Sciences, v. 5, n. 1, p. 1-5, 2011.

QUEIROZ, V. S. et al. Fasciola hepatica (Trematoda, fasciolidae): estudo epidemiológico nos municípios de Bocaiúva do Sul e Tunas do Paraná (Brasil). Acta Biológica Paranaense, v. 31, n. 1-2-3-4, p. 99-111, 2002.

SILVA SANTOS, L. C.; SCAINI, C. J.; RODRIGUES, L. A. F. Myocastor coypus (Rodentia Capromyidae) como reservatório silvestre de Fasciola hepatica (Lineu, 1758). Revista Brasileira de Parasitologia Veterinária, v. 1, n. 1, p. 27 30, 1992.

SOUSA, I. K. F. et al. Lesões hepáticas em bovinos abatidos sob inspeção federal em Santarém, região Oeste do Pará, Brasil. Veterinária e Zootecnia, v. 18, n. 4, supl. 3, p. 1145-1147, 2011.

YASGAN AKSOY, D. et al. Fasciola hepatica infection: clinical and computerized tomographic findings of ten patients. The Turkish Journal of Gastroenterology, v. 17, n. 1, p. 40-45, 2006. PMid:16830276.

Recebido: 29/05/2013

Received: 05/29/2013

Aprovado: $17 / 03 / 2014$

Approved: 03/17/2014 